\title{
Trend in malaria prevalence among children under five years of age in the Hadiya Zone, southern Ethiopia: a five-year retrospective study
}

\author{
ALEMU CHEMEDA IFA ${ }^{A, c-F}$
}

Department of Biology, College of Natural Science, Arbaminch University, Arbaminch, Ethiopia

A - Study Design, B - Data Collection, C - Statistical Analysis, D - Data Interpretation, E - Manuscript Preparation, F - Literature Search, G - Funds Collection

Summary Background. About $75 \%$ of the land and $60 \%$ of the population is exposed to malaria in Ethiopia. Malaria persists as a major health problem in the Misrak Badawwacho districts of the Hadiya Zone. In children under five years of age, malaria admissions and deaths fell by $81 \%$ and $73 \%$ respectively between 2001 and 2011 .

Objectives. The aim of this study was to determine the prevalence and trend in malaria parasite infection among pediatric patients treated in the Konga Health Center, Hadiya Zone, Misrak Badawwacho District, southern Ethiopia.

Material and methods. A retrospective analysis of pediatric patients' records was conducted between September 2011 and June 2015. The data was analyzed to determine malaria morbidity and trend in malaria prevalence among children under five years of age. Data analysis was performed using SPSS software version 20.

Results. A total of 5,210 medical records were retrieved and reviewed; the analysis showed that 2,459 patients (47.2\%) were positive for malaria infection, of which $57 \%$ were due to Plasmodium falciparum and $43 \%$ due to $P$. vivax. The analysis demonstrated that the cumulative prevalence of malaria has been decreasing, with the exception of 2012, when it was found to increase rapidly.

Conclusions. The prevalence of malaria in southern Ethiopia was found to be high and firmly associated with the closeness of potential mosquito breeding sites. The high incidence of the disease in this age group shows that malaria is endemic in the area. Both governmental and non-governmental organizations engaged in malaria campaigns should cooperate to raise awareness in the community and scale up the delivery of resources used for malaria control.

Key words: malaria, prevalence, Ethiopia.

Ifa AC. Trend in malaria prevalence among children under five years of age in the Hadiya Zone, southern Ethiopia: a five-year retrospective study. Fam Med Prim Care Rev 2018; 20(4): 337-340, doi: https://doi.org/10.5114/fmpcr.2018.79344.

\section{Background}

According to a World Health Organization (WHO) report, children under five years of age are the most vulnerable group affected by malaria. Out of 438,000 malaria deaths reported globally in 2015, nearly 69\% were in children under five years of age [1]. In Ethiopia, Plasmodium falciparum and $P$. vivax were responsible for approx. $60-70 \%$ and $30-40 \%$ of malaria cases, respectively [2].

P. falciparum has been the major cause of infections and the primary cause of deaths from malaria [3]. This is because the Anopheles arabiensis, the major vector of malaria in Ethiopia, has widespread geographical distribution. Ethiopia's Ministry of Health has been playing a great role in reducing malaria prevalence. Thanks to the Ministry's efforts, the number of villages affected by malaria epidemics decreased from 681 in 2004 to only 3 in 2008 [4]. However, malaria continues to be the main reason for outpatient consultations and hospital admissions in the country [5]. It is estimated that three-fourths of the land below 2,000 meters is malarious, and two-thirds of the country's population are at risk [6]. This is why malaria remains a number one health problem in Ethiopia, with an average of approx. 5 million cases a year [7]. It is estimated that the disease causes 70,000 deaths each year and is the reason for $17 \%$ of outpatient visits to health institutions. It also accounts for $15 \%$ of admissions and $29 \%$ of inpatient deaths [8].

Ethiopia has achieved remarkable progress in the fight against malaria in recent decade. As a result, between 2001 and
2011, malaria fatality and hospital admissions due to malaria in children under five years of age decreased by $81 \%$ and $73 \%$, respectively. The country has shown fantastic progress in combating malaria by achieving the MDG $6 \mathrm{c}$ goals: halting the spread and reducing the incidence of malaria and other endemic diseases by 2015 [9-14].

\section{Objectives}

There is very limited data on malaria prevalence in pediatric patients in different areas of the country. Therefore, this study was designed to estimate the prevalence of malaria in the pediatric population and to assess its seasonal variation. The issue of seasonal variation of malaria was addressed by conducting retrospective cross-sectional surveys for five consecutive years. This study provides information on the community-based prevalence and trend in malaria incidence among pediatric patients in endemic lowland areas in southern Ethiopia.

\section{Material and methods}

\section{Study area}

The study was carried out in the Konga Health Center and its catchment area of five health posts in five kebeles (an administrative district in Ethiopia), namely: Mehal Korga, Korga Beshilo, Abuka, Weldeya and Kumudo of the Misrak Badawwacho district, Hadia Zone, southern Ethiopia. 


\begin{tabular}{|c|c|c|c|c|c|c|c|c|c|c|}
\hline \multirow[t]{2}{*}{ Year } & \multirow{2}{*}{$\begin{array}{l}\text { Malaria } \\
\text { patients } \\
{[n]}\end{array}$} & \multicolumn{2}{|c|}{ Gender } & \multicolumn{3}{|c|}{ Age categories } & \multicolumn{2}{|c|}{ Types of malaria } & \multirow{2}{*}{$\begin{array}{l}\text { Malaria } \\
\text { prevalence }\end{array}$} & \multirow[t]{2}{*}{$p$} \\
\hline & & $M$ & $F$ & $>1$ & $1-2$ & $3-5$ & P. falciparum & P. vivax & & \\
\hline 2011 & 554 & 228 & 326 & 91 & 180 & 283 & $338(61 \%)$ & $216(39 \%)$ & $45 \%$ & 0.003 \\
\hline 2012 & 740 & 404 & 336 & 102 & 351 & 287 & 377 (51\%) & $363(49 \%)$ & $62 \%$ & 0.000 \\
\hline 2013 & 492 & 242 & 250 & 49 & 211 & 232 & 231 (47\%) & 261 (53\%) & $50 \%$ & 0.002 \\
\hline 2014 & 337 & 172 & 165 & 19 & 137 & 181 & $212(63 \%)$ & $125(37 \%)$ & $40 \%$ & 0.012 \\
\hline 2015 & 336 & 165 & 171 & 3 & 195 & 138 & $211(63 \%)$ & $125(37 \%)$ & $40.4 \%$ & 0.008 \\
\hline Total & 2,459 & 1,211 & 1,248 & 264 & 1,074 & 1121 & $1,402(57 \%)$ & $1,057(43 \%)$ & $47.2 \%$ & \\
\hline
\end{tabular}

\section{Study design}

An institution-based retrospective study was conducted between May 10 to June 16, 2015, to assess the trend in malaria prevalence among pediatric patients admitted to OPD and managed at the Konga Health Center.

\section{Study population}

The study population included pediatric patients admitted for malaria treatment from September, 2011 to June $13^{\text {th }}, 2015$.

\section{Inclusion criteria}

All patients aged 7 days -5 years, diagnosed and treated for malaria at the Konga Health Center Pediatric Unit.

\section{Exclusion criteria}

Neonates less than 7 days old and those more than 5 years old were excluded.

\section{Data collection instrument and procedure}

The target study populations were first identified from the registration books in wards and operation theatre. The patients' medical records were then retrieved, and the data were analyzed using a pre-prepared, structured questionnaire.

\section{Data entry and statistics}

The data collected was entered into Epi Data version 3.1 and exported to SPSS software version 16.0 for analysis. During analysis, descriptive statistics of frequency and percentage were used, and the outputs were displayed through tables.

\section{Data quality assurance}

During the preparatory stage, the questionnaires were carefully designed, pre-coded and pre-tested to minimize errors.

\section{Ethical consideration}

The study was approved by the Departmental Ethical Review and Research Committee (DERC) of the Arba Minch University,
College of Health Science (Protocol No. 3/J/2015, in meeting No. 23rd). No personal data was included in the questionnaire. Confidentiality of all the data was ensured throughout all the different stages of the study.

\section{Results}

Out of 5,210 malaria patients admitted between September 2011 and June 2015 at the Konga Health Center, 2,459 were children under five years of age $(47.2 \%$ of the study group; the median age -3 years). Of these, 1,211 were male $(50.8 \%)$. The prevalence of malaria infection each year was 45\% (2011), 62\% (2012), 50\% (2013), 40\% (2014) and 40.4\% (2015), respectively. Of the children under five years of age admitted to the Konga Health Center due to malaria, $57 \%$ were infected by $P$. falciparum, and $43 \%$ were infected by $P$. vivax (Table 1 ).

\section{Malaria trend in the Hadiya Zone}

There has been a gradual decline in malaria prevalence in the period 2012-2015 within the study area, except for the year 2012 (Figure 1). This decreasing trend was the result of raising public awareness by local health and administrative offices, as well as by continuing efforts that increased attention to malaria control and preventative activities by different responsible bodies in the catchment areas of the Konga Health Center. When analyzing the prevalence of malaria throughout the past fifty months, we observed an increasing trend in malaria prevalence from September to November, and a decreasing trend in the number of new cases from December to May. The number of malaria cases usually starts to grow in June (Figure 2).

\section{Discussion}

This study focused on the burden of malaria among children under five year of age. The prevalence of malaria infection among diagnosed children was high in the study area. Our study findings are consistent with the results obtained in another study conducted at a similar altitude in Ethiopia and another region in the world $[15,16]$. However, a higher prevalence was reported in Nigeria [17]. To ensure reliability, we used trusted sources of data collected by the residents of the study area and retrieved by trained professionals. Additionally, the assessment

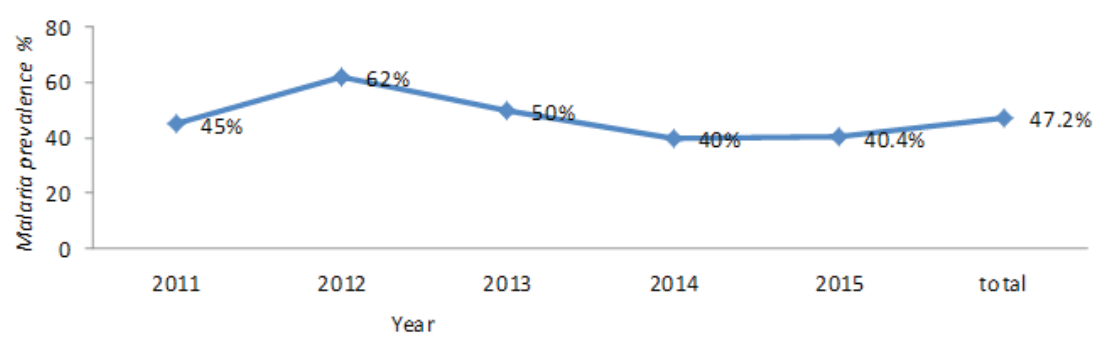

Figure 1. Trend in malaria prevalence among children under five years age in the Konga Health Center, 2011-2015 


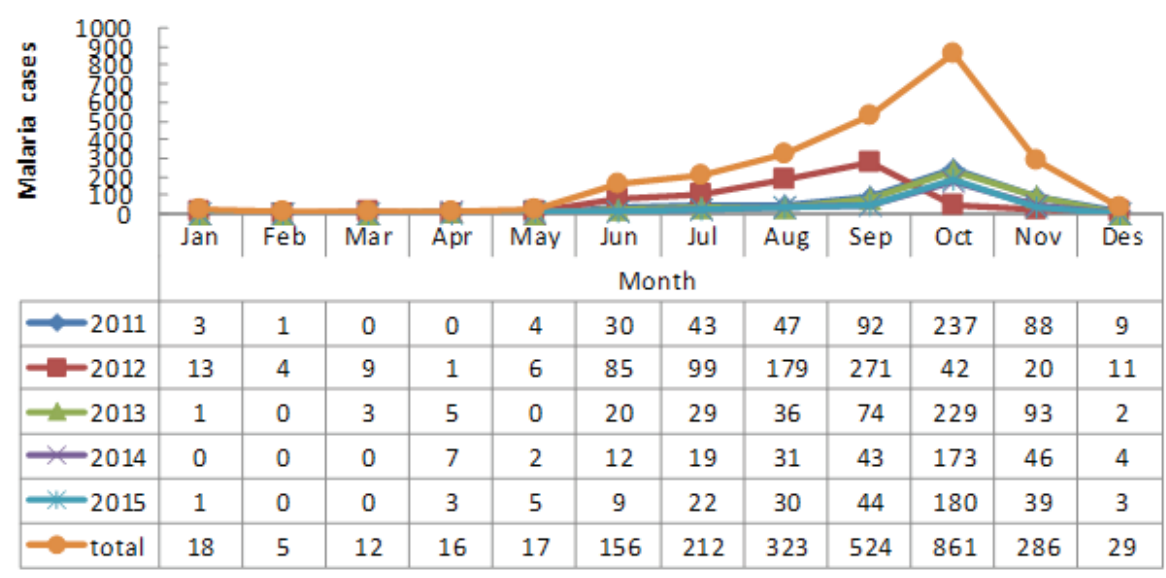

Figure 2. Five-year trend of malaria infections by month among children under five years of age in the Konga Health Center

of malaria prevalence in different seasons repetitively for five consecutive years provided solid information. Thus, this study provides a fair approximation of malaria prevalence in the study area. Malaria remains a burden to Ethiopia, especially among children [18], as they have lower immunity to malaria as a result of limited prior exposure to the disease. Malaria infection is a major problem of public health among children living in the Hadiya Zone between the lake and two rivers, where malaria is endemic. Malaria is commonly observed in lowland areas of Ethiopia [19]. The Hadiya Zone is a lowland region, and because of the proximity of two rivers and one lake in the area, the vector provides more favorable conditions for breeding. The occurrence of the disease among children under five years of age in this zone might indicate that malaria is indigenous to the area. However, people in the Ethiopian highlands, which were previously considered to be malaria free, were found to be at an increasing risk of malaria [19]. The prevalence of malaria has been found to vary depending on weather conditions. A high prevalence of malaria infection occurs after the rainy season $(54.5 \%)$ and following the onset of the rainy month (38.9\%). Similar findings were reported by other authors, who stated that the highest prevalence was found at low altitudes between October and November 2009 [19]. Therefore, identification of areas in which malaria cases are clustered might be helpful in planning focused interventions against malaria. The present results showed the seasonality of malaria transmission, and this is in concord with other studies $[2,20]$. The occurrence of malaria depends on sufficient rainfall and temperature. An increased prevalence in 2012 was registered because there were long rainy months, erratic rains in the dry season and a significant accumulation of water (e.g. swamps, marshes, stagnant roadside water and ponds) in the study area. These conditions favored the breeding of mosquitos in an unusual way. In areas with a temperate climate, the transmission of malaria is commonly limited to months in which the average temperature is above the minimum required for sporogony [21]. This explains the inverse relationship of decreasing malaria prevalence with increasing altitude.

In many African hospitals, $P$. falciparum malaria is a leading cause of admission of children and the chief cause of their deaths. Of the children under five years of age admitted to the Konga Health Center, $57 \%$ were infected by $P$. falciparum, and $43 \%$ were $P$. vivax - the diagnoses were based on the results of RDTs. Similar findings were reported from Rwanda [15]. As reported by the National Vector Borne Disease Control Programme (NVBDCP), around $50 \%$ of the total number of malaria cases reported in India was due to P. falciparum [22]. Similarly, as per the Strategic Action Plan for Malaria Control in India 2007-2012, the prevalence of $P$. falciparum has gradually increased from $38.8 \%$ in 1995 to $50 \%$ in 2008 [23], while the corresponding figures for the neighboring state of Chhattisgarh were $78.8 \%$ and $84.3 \%$, respectively [24].

Accordingly, over the last five years, the prevalence of malaria infection among children less than five years of age in the Misrak Badawwacho district was $47.2 \%$. The cumulative prevalence of malaria (assessed on the basis of clinical records compiled over the last fifty months) showed an increasing trend from September to November, a decreasing trend from December to May and the onset of an increasing trend in June. The overall trend in malaria prevalence in the study area was decreasing. This is due to the government policy which focused on disease prevention by raising public awareness through health extension workers and health development army volunteers providing community-based awareness at the household level [5]. Most of the local communities were aware of the transmission routes and the causes of malaria [11]. The prevalence of malaria infection among children under five years of age reaches two peaks within a single year. The lower peak is in May (at the onset of the rainy season), and the higher one between October and November (towards the end of the rainy season). These seasonal peaks are similar to the peaks of mosquito biting density found by other researchers in Pakistan, as well as by different authors reporting on seasonal peaks of malaria in other regions [25].

\section{Conclusions}

The prevalence of malaria in the Hadiya Zone was found to be high. This study revealed that $P$. falciparum is the dominant species in malaria endemic districts of Ethiopia. The trend of malaria infection in the study area has been decreasing due to the government policy of prevention of the disease by raising public health awareness. Such a high prevalence of malaria infections in the study area was strongly associated with the proximity of potential mosquito breeding sites. The occurrence of the disease among children under five would indicate that malaria is native to the area. The use of personal protection methods, such as insecticide-treated mosquito nets, should be promoted in the area, and malaria control interventions should target residents who live in close proximity to mosquito breeding sites. 


\section{References}

1. World Health Organization. WHO World Malaria Report. Geneva: WHO; 2015.

2. Chala B, Petros B. Malaria in Finchaa sugar factory area in western Ethiopia: assessment of malaria as public health problem in Finchaa sugar factory based on clinical records and parasitological surveys, western Ethiopia. J Parasitol Vector Biol 2011; 3(4): 52-58.

3. Kiszewski AE, Teklehaimanot A. A review of the clinical and epidemiologic burdens of epidemic malaria. Am J Trop Med Hyg 2004; 71(2 Suppl.): 128-135.

4. Jima D, Getachew A, Bilak H, et al. Malaria indicator survey 2007, Ethiopia: coverage and use of major malaria prevention and control interventions. Malar J 2010; 9: 58, doi: 10.1186/1475-2875-9-58.

5. Ministry of Health. Health and health-related indicators, 2008/2009 Addis Ababa, Ethiopia. Addis Ababa: MOH; 2010.

6. Negash K. Ethiopia roll back malaria consultative mission: essential actions to support the attainment of the Abuja targets. Ethiopia RBM Country Consultative Mission Final Report 2004: 39.

7. Senay G, Verdin J. Developing a malaria early warning system for Ethiopia. National Center for EROS; 2005: UC2409.

8. MHE. President's Malaria Initiative, Malaria Operational Plan Malawi FY 2008. 2008.

9. Das N, Baruah I, Kamal S, et al. An epidemiological and entomological investigation on malaria outbreak at Tamulpur PHC, Assam. Indian J Malariol 1997; 34(3): 164-170.

10. Dev V, Sharma V. Persistent transmission of malaria in Sonapur PHC, Kamrup district, Assam. J Parasitic Dis 1995; $19: 65-68$.

11. Dutta $\mathrm{P}, \mathrm{Khan} \mathrm{A}, \mathrm{Mahanta} J$. Problem of malaria in relation to socio-cultural diversity in some ethnic communities of Assam and Arunachal Pradesh. J Parasitic Dis 1999; 23(2): 101-104.

12. Prakash A, Mohapatra P, Bhattacharyya D, et al. Changing malaria endemicity - a village based study in Sonitpur, Assam. $J$ Commun Dise 1997; 29(2): 175-178.

13. Shukla R, Pandey A, Mathur A. Investigation of malaria outbreak in Rajasthan. Indian J Malariol 1995; 32(3): 119-128.

14. Srivastava $H$, Kant $R$, Bhatt $R$, et al. Epidemiological observations on malaria in villages of Buhari PHC, Surat, Gujarat. Indian J Malariol 1995; 32(4): 140-152.

15. Gahutu JB, Steininger C, Shyirambere $C$, et al. Prevalence and risk factors of malaria among children in southern highland Rwanda. Malar J 2011; 10: 134, doi: https://doi.org/10.1186/1475-2875-10-134.

16. Qureshi IA, Mohtashim A, Qureshi RK, et al. Prevalence of malaria infection among under five year tribal children residing in malaria endemic forest villages. F1000Research 2014; 3: 286, doi: 10.12688/f1000research.5632.1.

17. Akinbo FO, Omoregie R, Mordi R, et al. Prevalence of malaria and anemia among young children in a tertiary Hospital in Benin City, Edo State, Nigeria. Fooyin J Health Sci 2009; 1(2): 81-84.

18. Dzeing-Ella A, Obiang PC, Tchoua R, et al. Severe falciparum malaria in Gabonese children: clinical and laboratory features. Malar J 2005; 4: 1, doi: 10.1186/1475-2875-4-1.

19. Woyessa A, Deressa W, Ali A, et al. Prevalence of malaria infection in Butajira area, south-central Ethiopia. Malar J 2012; 11(1): 84, doi: doi: 10.1186/1475-2875-11-84.

20. Tesfaye S, Belyhun Y, Teklu T, et al. Malaria prevalence pattern observed in the highland fringe of Butajira, Southern Ethiopia: a longitudinal study from parasitological and entomological survey. Malar J 2011; 10: 153, doi: 10.1186/1475-2875-10-153.

21. Molineaux L. The epidemiology of malaria as an explanation of its distribution, including some implications for its control. In: Wernsdorfer W, ed. Malaria Principles and Practice of Malariology. Edinburgh: Churchill Livingstone; 1988: 913-998.

22. NVBDCP. National Vector Borne Disease Control Programme. New Delhi: Shamath Marg; 2013: 22.

23. NVBDCP. Strategic Action Plan for Malaria Control in India 2007-2012. Scaling up malaria control interventions with a focus on high burden areas. Delhi: Shamath Marg; 2014.

24. NVBDCP. National Vector Borne Disease Control Programme. $22^{\text {nd }}$ ed. New Delhi: Shamath Marg; 2014: 37.

25. Roland M, Hewitt S, Durani N, et al. Transmission and control of vivax malaria in Afghan refugee settlements in Pakistan. Trans $R$ Soc Trop Med Hyg 1997; 91: 252-255.

Tables: 1

Figures: 2

References: 25

Received: 26.06 .2018

Reviewed: 10.07 .2018

Accepted: 01.08.2018

Address for correspondence:

Alemu Chemeda Ifa, Msc

Arbaminch University

College of Natural Science

Department of Biology

P.O. Box: 21

Block 202, office 16

Arbaminch, Ethiopia

Tel.: +251910337785

E-mail: alemuchemedaifa@yahoo.com 